\title{
Me, Myself and My Brain Implant: Deep Brain Stimulation Raises Questions of Personal Authenticity and Alienation
}

\author{
Felicitas Kraemer
}

Received: 4 December 2010 / Accepted: 20 April 2011 /Published online: 12 May 2011

(C) The Author(s) 2011. This article is published with open access at Springerlink.com

\begin{abstract}
In this article, I explore select case studies of Parkinson patients treated with deep brain stimulation (DBS) in light of the notions of alienation and authenticity. While the literature on DBS has so far neglected the issues of authenticity and alienation, I argue that interpreting these cases in terms of these concepts raises new issues for not only the philosophical discussion of neuro-ethics of DBS, but also for the psychological and medical approach to patients under DBS. In particular, I suggest that the experience of alienation and authenticity varies from patient to patient with DBS. For some, alienation can be brought about by neurointerventions because patients no longer feel like themselves. But, on the other hand, it seems alienation can also be cured by DBS as other patients experience their state of mind as authentic under treatment and retrospectively regard their former lives without stimulation as alienated. I argue that we must do further research on the relevance of authenticity and alienation to patients treated with DBS in order to gain a deeper philosophical understanding, and to develop the best evaluative criterion for the behavior of DBS patients.
\end{abstract}

F. Kraemer $(\bowtie)$

Philosophy \& Ethics,

Eindhoven University of Technology,

IPO 1.01, PO Box 513, 5600 MB Eindhoven,

The Netherlands

e-mail: f.kraemer@tue.nl
Keywords Deep brain stimulation - Authenticity Alienation · Autonomy · Brain pacemaker · Implant ethics

\section{Introduction: Problems of Authenticity and Alienation in the Use of DBS}

Outline of the Paper

Deep brain stimulation (DBS) is a practice that has been used since the late 1980s mainly for Parkinson patients, but also for the treatment of diseases such as epilepsy and for the experimental treatment of psychiatric and other diseases (cf. [1, 2]). ${ }^{1}$ In DBS for Parkinson patients, a so-called 'brain pacemaker' is implanted, and its electrodes in the brain stimulate either the subthalamic nucleus or the globus pallidus ([3]: 533ff.) in order to treat movement disorders, tremors, and freezing that are typical for Parkinson's disease. While DBS can vastly improve motor abilities, it is well-known that DBS can also have psychiatric side-effects, such as hypomania and manic

\footnotetext{
${ }^{1}$ A version of this paper was given at a conference in Delft in 2009 and at a workshop on self \& psychological alienation held in Dortmund, July 2010, as part of the New Thinking on Alienation Research Networking Project funded by the AHRC. I wish to thank the audiences for their helpful remarks. My special thanks go to Oliver Hallich, Alexander Bagattini, and Samantha Matherne for their comments on earlier drafts of this article.
} 
episodes ([4], cit in [5]). The fact that DBS as a treatment sometimes brings about personality changes invites philosophical considerations about problems of personal authenticity and alienation in this context. It raises the question of whether, under treatment, patients feel no longer like themselves. In other words, we may wonder whether under treatment patients can remain, authentic 'or become, alienated' from their true selves (notions I define below in Section Felt Authenticity and Felt Alienation: Some Conceptual Clarifications).

In order to bring out the relevance of the notions of authenticity and alienation to the neuro-ethics of DBS, I focus on several case studies of patients under DBS treatment (cf. [6]). What is significant about these narratives is that they each involve elements of authenticity and alienation, although not in a uniform way. Some patients claim under treatment that they feel authentic, i.e. like themselves, and regard their life with Parkinson's disease retrospectively as a time of alienation. Other patients, however, claim that the treatment deprives them of their authenticity and that they no longer feel like themselves when under DBS. As a first approximation, one could say that it seems as if DBS could threaten authenticity and bring about alienation in some cases, whereas it generates feelings of authenticity in others.

Accordingly, in this article, I argue for the following thesis: We should take into consideration patients 'feelings of authenticity and alienation when talking about the chances and challenges of deep brain stimulation. The concepts of authenticity and alienation are useful heuristic tools not only for a better philosophical understanding of the patients' experience of DBS, but also, in some cases, the use of these concepts can even lead to a re-evaluation of the treatment and its side-effects, and should, therefore, contribute to future ethical reflection on DBS.

While it is not my aim in the current paper to suggest specific ethical guidelines for treatment, I do wish to suggest that future ethical discussions will profit by considering the notions of authenticity and alienation, which I outline here. I argue that we must do further research on the relevance of authenticity and alienation to patients treated with DBS in order to gain a deeper philosophical understanding, and to develop the best evaluative criterion for the behavior of DBS patients. If research supports the thesis of the present article, then the tools psychologists and doctors currently use to evaluate DBS patients should be complemented by philosophical considerations, because the medical accounts alone are failing to take into account the important subjective-dimensions of authenticity and alienation. This is deeply problematic because it doesn't give the doctor, patient, or family involved the fullest sense of what is going on, nor does it give them clear guide-lines for how to evaluate the patient's behavioral changes.

While there is indeed a plethora of literature on the ethics of DBS, there is not much literature that deals specifically and systematically with the questions of authenticity and alienation, as I do here. An exception is the recent article on narrative identity and selfexperience under DBS by Müller et al. [7] that brings in the concepts of authenticity and alienation. Many of its findings support the thesis of the present article. $^{2}$ However, the majority of authors tackle issues related to authenticity in the context of DBS, such as personal identity ${ }^{3}$ [8-11], patient autonomy and responsibility [1, 2, 12, 29, 35, 36], and happiness (cf. [13]) without actually focusing on authenticity. ${ }^{4}$ Meanwhile, Carter et al. raise the problem of authenticity in the context of the medication of patients with dopamine sensitive drugs, but not in the context of DBS [14]. Finally, Bolt brings up the issue of authenticity in the context of neuroenhancement [15]. However, with the exception of Müller et al. [7], none of these recent articles on authenticity and neuro-ethics focus primarily on

\footnotetext{
$\overline{2}$ The article by Müller et al. [7] interprets new and original empirical material from patient interviews conducted in the Charité in Berlin. It does not deal with the article from Schüpbach et al. [6] that is central for the present article. Schermer [13] brings up the notion of authenticity in the context of DBS as well, but without going into detail about it. Schermer seems to bring 'authenticity' very close to 'autonomy' and lies her focus on the latter.

${ }^{3}$ Problems of authenticity should be distinguished from problems of identity because the question of identity in the classical Lockean sense is primarily one of numerical identity over time. In contrast, the key-question of authenticity is which of the different 'selves' can count as the 'real' one, i.e. the true self.

${ }^{4}$ Schechtman [9]: 136ff. interprets the case studies by Schüpbach et al. as well. Her notion of personal identity sometimes comes close to what I regard as authenticity; however, she does not go into detail about these and similar terminological points. On her understanding, a patient's 'true self' is what is at stake once sudden personality changes take place under treatment. For a psychiatric account of autonomy and mental competence, see [29].
} 
DBS. $^{5}$ By my lights, this is a gap in the literature, which this article attempts to begin filling in.

In order to support my view, I begin, in Section Felt Authenticity and Felt Alienation: Some Conceptual Clarifications, by giving a minimalist definition of what I mean by the concepts of authenticity and alienation. In section A Philosophical Interpretation of Some Case Studies from Schüpbach et al. [6], I then present three case studies from a psychological report by Schüpbach et al. [6], offering a philosophical analysis of these cases in light of authenticity and alienation. In Section Conclusions, some conclusions follow: When analyzing the case studies from a philosophical point of view, aspects of the patients' experience are emphasized, which are not fully appreciated in the psychological assessment. As we will see, for many of the patients, their experience involved recognizing, exploring, and enacting what they regarded as their 'true selves'.

The most important aim of this paper is to bring out a subjective side of DBS treatment, which has so far not received the attention that it ought to receive. My goal in presenting these case studies is to illuminate the ways in which the subjective notions of authenticity and alienation are relevant to the philosophical and ethical discussion of DBS, as well as to how we are to evaluate the behavior of DBS patients.

Felt Authenticity and Felt Alienation:

Some Conceptual Clarifications

The terms 'alienation' and 'authenticity' have a long philosophical history and have been recently revitalized in current debates in social and moral philosophy. While the concept of 'alienation' has its roots in Marxism, it has recently gained purchase in current discussions in social philosophy (cf. 39). Meanwhile, the concept of 'authenticity' with its rather heterogeneous roots in the work of St. Augustine, JeanJacques Rousseau, and existentialist writers such as Kierkegaard, Heidegger, and Sartre, has gained more and more attention in recent decades, beginning with Lionard Trilling's famous lectures on sincerity and

\footnotetext{
${ }^{5}$ Other recent articles focus on authenticity within the broader context of neuro-ethics and neuro-enhancement or special fields within both. Among them are Bublitz \& Merkel [23], Kraemer [27], and Erler [30].
}

authenticity as moral ideals ([16]; cf. [17]: 46). ${ }^{6}$ Indeed, 'authenticity' underwent a renaissance in the 1980s, triggered by Charles Taylor's Sources of the Self [18] and The Ethics of Authenticity [19] (cf. also [20]: 29f.), and, even now, we see it playing a role in important debates in bio-ethics, which I discuss below. However, in spite of the resurgence of these concepts in contemporary debates, 'authenticity' and 'alienation' are notoriously vague concepts, and I want to offer some preliminary remarks to clarify how I will be using them here.

In general, I regard authenticity and alienation as felt mental states, where authenticity is indicated by a person saying things such as 'I feel like myself', and alienation is indicated by statements such as 'I am not myself' or 'I am no longer myself'. On my interpretation, authenticity and alienation are opposites: a person who is authentic is not alienated, and vice versa. In other words: 'alienation' here means 'inauthenticity'. Moreover, I take authenticity and alienation to be experiences, which involve an important normative dimension: we experience authenticity as something we ought to strive for, whereas alienation is experienced as something we ought to avoid. In this regard, my account draws on Trilling's and Taylor's views of authenticity and Rahel Jaeggi's account of alienation, which I discuss below. That being said, while authenticity and alienation are indicated by the above kind of statements, this does not mean that they are simple phenomena. As I suggest in what follows, the experience of authenticity and alienation are multidimensional, and, although, I take my starting point from the above mentioned feelings of being 'myself' or 'not myself', I think it best to keep the details of these experiences fairly flexible and wide open, at least for now. In what follows, I treat these two notions in a normative way, i.e. I regard authenticity as a state to be striven for, and alienation as a state to be avoided or overcome.

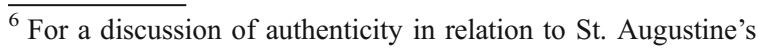
notion of the human soul, its relation to God, and the ,highest goal in life', see [41]: 15 ff., [40], and [22]: 174. For a discussion of Rousseau's idea of the authentic state of mind as the one in which the individual has stripped off her societal bonds and has returned to a natural mode, free from social coercion and deceit, see [41]: 55-60; [17]: 33f.. And, for the discussion of existentialism and authenticity, see [41]: 132-4; 143-5; 149-151, and [40], mentioned below.
} 
Therefore, before we proceed, I want to say a bit more about the 'normative' connotations I take to be built into the notions of authenticity and alienation, for this is a contentious issue. Let's begin with the normative underpinnings of authenticity. As mentioned before, the more recent use of 'authenticity' as a normative term can be traced back to Trilling's lectures, where he argues that authenticity is a moral ideal ([16]; cf. [17]: 46). This normative use of authenticity was furthered in Taylor's work, The Ethics of Authenticity [19], where he describes how authenticity became a moral ideal, especially in the United States (cf. also [20]: 29f.). Between the work of Trilling and Taylor, then, the notion 'authenticity' has emerged or re-emerged as a normative concept, capturing a moral ideal that a person ought to strive for and a virtue one ought to possess ([41]: 2).

Even more recently, authenticity construed in this normative fashion has shaped debates in applied ethics, in particular, the organ transplantation debate and the debate about enhancement. In the debate about organ transplantation, authenticity plays a role, insofar as the question has been raised concerning when a patient regards her transplanted organ as a part of her real self, and the ethical issues that arise accordingly (cf. [21]). Meanwhile, in the enhancement debate, the notion of authenticity plays a major role as well, where the question has been raised concerning whether enhancement interventions lead to the revelation of the 'true self', e.g. whether the intake of lifestyle drugs, such as the antidepressant Prozac, leads to 'feelings of authenticity' (cf. e.g. [17, 22]). As Carl Elliott puts it in Better Than Well: American Medicine Meets the American Dream: 'The ideal of authenticity drives much of the language that patients and clients use to describe their use of enhancement technologies. Technologies from Prozac to face-lifts are routinely described as tools of selfdiscovery and self-fulfilment' ([17]: 30). In this context, enhancement has been regarded positively as a means to achieving the ideal of authenticity and as something that enables self-realization.

By my lights, what we see in both bio-ethics debates is that the notion of 'authenticity', construed in a normative fashion and understood as selfrealization, is helpful in our efforts to understand the ethics of the medical interventions at stake. Indeed, as I will show in this article, the normative notion 'authenticity' can be fruitfully applied to the topic of DBS. ${ }^{7}$ As we will see, some reports suggest that some DBS patients feel that they have found their 'real', 'better' or even 'ideal selves' under treatment. ${ }^{8}$ This suggests that, under therapy, they have become how they always wanted to be and call this their 'real selves'. Such an experience accompanying a neurointervention is oftentimes facilitated by increasing feelings of self-confidence and self-love (cf. [22]: 175). Thus, DBS seems to allow some patients to achieve 'authenticity' and achieve the ideal they have been striving for.

However, it should be noted that some authors express doubts whether 'authenticity' is a normative concept and whether it should play a prominent role for ethical assessment at all (cf. [23]). For them, 'authenticity' is just a synonym for a positive, pleasant state of mind and, therefore, a superfluous notion. Accordingly, for them, it is not a normative concept and should not be used for ethical assessment.

A way to meet this objection is to point out that on my interpretation, authenticity involves feeling like oneself, but this does not necessarily mean that this is a pleasurable experience. In other words, the feelings of pleasure sometime come apart from the feelings of 'like myself'. Vice versa, a state of alienation can even be subjectively experienced positively - Heidegger's 'Das Man' would be a good example. Yet, some authors who want to discard 'authenticity' as a normative notion in ethical debates actually use this idea to their advantage. For them, the very fact that 'authenticity' can designate something negative is a sign that it cannot be taken seriously as a normative concept at all, because if it isn't

\footnotetext{
$\overline{{ }^{7} \text { Still, one has }}$ to keep in mind that DBS as the topic of the present paper is nowadays normally used for treatment and not enhancement purposes. DBS involves surgery, which usually implies considerable health risks. It is, therefore, unlikely that it will enter the enhancement market easily. Cf. [17]: 156 deals with a fictitious technology that resembles a brain pacemaker, but is used as a technology for mood enhancement, especially among elderly people who feel alienated from their lives spent in nursing homes.

${ }^{8}$ A discussion of the notoriously difficult distinction between one's 'real self' and one's 'ideal self' goes beyond the scope of this paper, but has been discussed in the literature. As e.g. [20]:30 points out, numerous 'restauration narratives' in which people tell how they felt before and after enhancement interventions actually bring up a 'true self' that had allegedly existed before during their lives, whereas in fact they have rather reached a ideal state through means of enhancement.
} 
something desirable, it isn't clear how it could be a virtue to seek or an ideal to pursue.

I think these objections are valuable insofar as they press on the fact that it is very difficult to identify what exactly is involved in the feeling of authenticity. This is due, in part, to the fact that the concept of authenticity is an amalgam arising out of different traditions, each of which uses the concept to identify different phenomena. And, insofar as we have inherited the notion from these traditions, our own understanding of authenticity does and should reflect these multiple dimensions of authenticity. Indeed, authenticity cannot be distilled to one particular, simple phenomenon; rather, it is a complex phenomenon, with many different aspects and sides.

Nevertheless, it is my view that there is a complex phenomenon associated with 'authenticity', which has normative underpinnings and promise as a tool in ethical assessment. This has been borne out in the recent debate over enhancement. As mentioned before, in this debate, we have seen the notion of authenticity gain purchase because it has proven to be useful in the efforts to describe numerous relevant phenomena, phenomena which are crucial to understanding the ethics of enhancement (cf. [24]). Given these promising results in the enhancement debate, we have reason to be hopeful that the notion of 'authenticity', used in the positive, normative sense can shed light on our understanding of the ethics of DBS. Indeed, as we will see in the case studies below, some patients claim to feel like they have found their 'true selves' or 'ideal selves' and cite this as a desirable outcome of their treatment, which suggests that authenticity, normatively construed, does have purchase in the debate over DBS. ${ }^{9}$ In the end, though, while the notion of authenticity should play a part in these debates, in order to do justice to its various aspects, it seems wise to keep the exact meaning of 'authenticity' as open and flexible as possible at the beginning. Still, the common starting point for my analysis of the case studies will be the normative

\footnotetext{
${ }^{9}$ This use of the term is in accordance with numerous case studies and considerations discussed in the enhancement debate (cf. [31] and [32]). However, the fact that 'authenticity' usually has normative connotations does not mean that one is immediately entitled to draw normative conclusions from the results in this article. As mentioned above, I am not providing ethical guidelines, but rather merely describing phenomena of felt authenticity and alienation.
}

notion that centres around a patient feeling 'like herself' after treatment.

Turning our attention now to the notion of 'alienation', as I said before, I take this to be a felt state, which is the opposite of authenticity, indicated by statements such as 'I no longer feel like myself'. Just as with 'authenticity', it is a mistake to think that 'alienation' is a simple, straightforward feeling; rather, it too is a multi-dimensional phenomenon. My understanding of it comes close to what Jaeggi defines in a recent monograph on alienation as 'a relation of relationlessness' (in the German: 'eine Beziehung der Beziehungslosigkeit'; [25]: 12). ${ }^{10}$ More precisely, Jaeggi claims, 'alienation is said to consist in a distorted relation to oneself and to one's world that can be characterized as the failure adequately to appropriate oneself or the world, to make oneself or the world 'one's own'. ${ }^{11}$ As she suggests, a feeling of alienation from oneself is often intimately connected with feeling alienated from things closely related to a person, i.e. from her own body, from her work, from social relationships, or from her partner and family. ${ }^{12}$ This feeling of alienation has negative consequences, such as the following suggested by Frederick Neuhouser: 'a sense of meaninglessness or estrangement, a loss of power in relation to self and world, and a subjugation to the products of one's own activity' [26]. As will become clear later on, exactly these feelings play a key-role in the DBS narratives. Moreover, just as with 'authenticity', it seems 'alienation' has potential in certain bio-ethics debates, because if a patient feels alienated as a result of treatment, this should be taken into considerations in our normative assessment of those treatments.

So far, I have suggested that authenticity and alienation are normative notions that turn on subjective self-ascriptions; however, it should be noted that a person's self-assessment can, of course, conflict with what other people say about her, be it family or friends. Although self-acclaimed authenticity is a subjective notion, this does not rule out the possibility

\footnotetext{
${ }^{10}$ Jaeggi [25], 'Entfremdung', cf. for the English translation of the terms cf. review by Neuhouser, Fredrick [26] from whom the quoted sentence stems.

${ }^{11}$ Neuhouser [26] about Jaeggi [25].

12 The relation between a person and her work life is an especially important one in the historical debate, in which alienation of a person from her work is usually construed as the starting point of an alienating self-relation.
} 
that other people can reasonably contribute to a person's self-understanding and, to some degree, can even intersubjectively correct it (cf. [27]). As the first three case studies show, the first- and the third-person perspective (i.e. the one of family members, doctors, and psychologists) and their respective ascriptions of authenticity to a person can differ sharply when it comes to assessing whether a person is authentic or alienated.

Ultimately, the aim of the present article is to shed some light on the normative underpinnings of the dimensions of felt-authenticity and felt-alienation of DBS patients in order to show that these notions should play a key role in the ethical debate about DBS - a discussion that has up to now mainly centered round the concepts of autonomy and responsibility.

\section{A Philosophical Interpretation of Some Case Studies from Schüpbach et al. [6]}

\section{The Case Studies}

In what follows, I present and interpret three case studies of patients who experienced behavioral changes after DBS treatment. These case studies stem from an article by Schüpbach et al. [6] in the journal Neurology. In that article, Schüpbach et al. report their findings from a study conducted by psychologists, neurologists, and a psychiatrist between 2000 and 2003 of 29 Parkinson patients (15 male, 14 female) treated with DBS. The interview technique is described as '[r]epeated open, unstructured interviews conducted by trained psychologists [...], neurologists [...], and a psychiatrist [...]' in order to 'qualitatively assess the impact of STN stimulation on the patients' personal, marital, and socio-professional life.'([6]: 1811f.). ${ }^{13}$ The original aim of the study was to 'prospectively examine 'kinds of social maladjustment

\footnotetext{
${ }^{13}$ STN (subthalamic nucleus stimulation) is a type of DBS, cf. [9]: 136.

${ }^{14}$ The results of these case studies stem from a small study and, as such, they should not be over-generalized (cf. [33] with respect to the selective use of individual empirical studies). The aim of this article is to present some first reflections based on similar cases that can only prove their validity in future case studies.
}

experienced by 29 patients with PD before and 18 to 24 months after bilateral STN stimulation' ([6]: 1811, my italics, FK). ${ }^{14}$

However, I argue that the emphasis on the notions 'social adaptation' and 'maladaptation' or 'maladjustment' fails to capture an important dimension of the patients' experience, namely, the subjective experience of authenticity and alienation. Accordingly, I offer a different interpretation of these cases, relying on the heuristic tools of authenticity and alienation, which aims at showing that the application of these concepts makes the content of the case studies more accessible to philosophers and ethicists, and, moreover, reveals that what the psychologists interpreted as 'maladaption' can, in fact, be interpreted in a different and positive philosophical light. This suggests that maybe we need to construct new tools for evaluating patients' behavior in the future, which reflect not only the third-personal 'adaption' criteria, but also the first-personal self-ascriptions of authenticity and alienation. We are now in the position to look at some case-studies.

Patient 1: 'I don't recognize myself anymore, [...] I feel like a machine,15

Patient 1, a 38-year-old female journalist married with one child, had PD (caused by a mutation in the parkin gene) for 30 years [...] with motor fluctuations and severe dyskinesias. Before stimulation, in spite of her motor handicap, she was dynamic: 'Combating the disease gave meaning to my life. I hope that stimulation will allow me to get on with my life and my projects. 'Six months after the operation, the patient was not satisfied in spite of a $75 \%$ improvement of her motor handicap and the withdrawal of her antiparkinson medication. She complained that the stimulator was not well programmed and she wanted to be able to adjust it herself at home. After 18 months of stimulation, she was no longer able to work, had a loss of inspiration and a taste for her work and for life in general. 'Now I feel like a machine, I've lost my passion. I don't recognize myself anymore. 'Her family no longer interested her, she was easily exhausted, and had a

\footnotetext{
$\overline{15}$ The subtitles are introduced by the author of the present article to structure the cases.
} 
loss of vitality (in the absence of a depressive syndrome), which led her to interrupt all professional activity. In short, a loss of vitality and a goal in life occurred despite major improvement of her motor symptoms by STN stimulation. ([6]: 1812).

A short analysis of this case reveals that four elements of felt-alienation and the loss of authenticity are at work in the patient's experience:

First, after successful treatment, the patient feels alienated from her work and indulges in leisure activities instead. ${ }^{16}$ This will be surprising to the reader given that she proclaimed that one of her main aims in undergoing the treatment was enhancing her ability to work. However, although her motor disability has improved remarkably, she nevertheless experiences her formerly much-beloved work as alienating after surgery.

Second, she experiences alienation from herself because she has lost a goal in life. It seems that this is the case because she no longer has anything to fight for and this has resulted in a loss of energy. She even goes so far as to say, 'I don't recognize myself anymore' - presumably because she used to be goal-oriented and energetic, but now has lost her drive, which she identified with. This corresponds with what Schüpbach et al. [6] suggest:

Fighting PD was a driving force for many patients that was frustrated in $12(41 \%)$ after surgery $[\ldots]$ causing disorientation. As expressed by another patient: 'Before stimulation, I wanted to be like everybody else, I didn't want to be considered only as sick. I fought for that every day! Now I find myself less impassioned, I regret the period where I did battle. Now it's the warrior's repose, I no longer have something to struggle against, my life is empty. I get up every day, but have no goal, no horizon.' ([6]: 1814).

Third, the patient feels alienated because she feels heteronomous - 'like a machine', as she puts it. The case report does not give any details, but this may be due to the fact that a mechanical device is implanted

\footnotetext{
${ }^{16}$ In the Introduction, I drew a distinction between alienation from work and alienation from self. The connection of both deserves closer discussion in the future.
}

in her brain. Phenomenologically speaking, it could be that the patient perceives the device as an alien technology that, as it were, remote-controls her feelings, behavior and thoughts (cf. [21]: $169 \mathrm{ff}$.) ${ }^{17}$. Another patient reports feeling 'like an electronic doll' ([6]: 1815). As Schüpbach et al. put it: 'The altered body image may result from difficulty in accepting psychologically the implanted material, as previously described in patients with pacemakers and implantable cardioverter defibrillators. ${ }^{18}$

What is interesting here, however, is that the selfdescription of some patients of being remotecontrolled by an electronic device runs contrary to the patients' actual gain in autonomy, because their motor abilities usually improve remarkably under treatment. In a certain sense, patients become more autonomous after successful surgery because they have a better command of their body. But in another, Aristotelian sense, a feeling of heteronomy arises: if a person is not entirely 'self-moved', but is or feels moved by a force outside her control, she might feel heteronomous. In this case study, the feeling of heteronomy goes hand in hand with the patient feeling alienated from life.

Fourth, this case raises another key issue involving authenticity and alienation: the split between mind and body. The authors of the study even chose this phenomenon to be the report's subtitle: 'A distressed mind in a repaired body'. They reveal that some patients experience feelings of alienation from their improved health condition. As the authors also report about other patients, some of them do not yet dare to trust their bodies and are aware of the fact that their disease will come back at some point ('negative

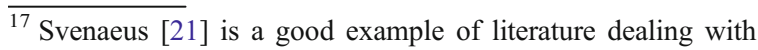
the question of embodiment from a phenomenological perspective that pays attention to patients' subjective feelings. Dealing with the case of organ transplantation, Sveneaus emphasizes that the relation of a person towards her own body is meaningful with respect to her relation to the world. From this point of view, we are our bodies, rather than possessing them. Svenaeus does not explicitly tackle problems of alienation and authenticity, but alludes to the fact that receiving someone else's organs could change a person's self-image as a whole. In a similar vein, the same could hold for the implantation of a device such as a brain pacemaker.

${ }^{18}$ Nevertheless the researchers remark that 'it is surprising that this difficulty was not observed in a greater number of patients' ([6]: 1815). In Müller et al. [7] one finds ambivalent accounts of patients' coping with the feeling of being alienated from their own bodies.
} 
anticipation'). 'In spite of successful surgery, 8 patients $(28 \%)$ felt mentally unable to resume a more normal life style. Although with STN stimulation they could, they did not dare to perform activities that had been impossible with PD before surgery. Past experience led to a negative anticipation that was objectively unjustified after surgery. 'My body is cured, but my mind is still sick,' said one patient ([6]: 1814). This is exemplified by Patient 1: although she describes herself as physically healed, her psychological condition cannot catch up to this new bodily state. This results in a feeling of alienation because the patient experiences her body as being in a state different than the one of her mind. ${ }^{19}$

To sum up these findings, this first case study shows a patient who, under treatment, has lost her felt-authenticity and eventually feels alienated from herself in several respects. After treatment, not only does her work-life seem alienating, but also she feels alienated from life-goals she identified with, as well as from her new, improved body (cf. [6]: 1814). ${ }^{20} \mathrm{In}$ the following case study, however, the patient experiences an opposite result.

\footnotetext{
${ }^{19}$ Here, it has to be remarked that DBS is by no means a cure. It only helps to control some symptoms, but the neurodegenerative disease is still there and progresses. Some symptoms are under better control through stimulation than before by medication. Therefore, the patient's utterance is not to be taken literally, nor is the title of Schupbach's et al. 'A distressed mind in a repaired body'. Whenever the present article talks about the 'healed' or 'cured' body after DBS, this is to be understood in a figurative way: some patients might indeed feel cured, because some of their preeminent symptoms are under better control and they are able to resume to their former lives.

${ }^{20}$ In this vein, what is especially interesting about DBS in comparison to other neuro-interventions is the interaction between internality and externality of a neuro-technology with respect to the human body. This can best be explained if one compares DBS to transcranial stimulation. On the one hand, via DBS, the patient herself, or another person, can change the patient's mental state by switching the pacemaker on or off from the outside. In this respect, DBS brings about similar results like transcranial stimulation with which one can influence cognitive performance and emotions from the outside. On the other hand, in the case of DBS, the pacemaker and the electrodes have become a part of the patient's brain and body, and the technology is 'internal'. By contrast, transcranial stimulation is an externally applied intervention that does not merge with the body and its functions. In the case of DBS, the interaction on of internality and externality brings about especially interesting questions of authenticity that have to do with the alienation some DBS patients feel from their own bodies and states of mind.
}

Patient 2: 'During all these years I was asleep, now I am going to take my life in hand, my life before PD'

'Patient 2, a 48-year-old male accountant, worked half-time for 7 years because of PD [...]. Before the operation, his wife assisted him in all tasks of daily living, assumed all domestic and financial responsibilities, spent hours with him, and helped him to conceal his disease from his entourage. After 18 months of stimulation, his motor condition was much improved [...]. The patient regained confidence in himself and aspired to more autonomy: 'I want to recover my social standing and establish new relationships outside my couple. During all these years of illness, I was asleep. Now I am stimulated, stimulated to lead a different life.' Confronted with the radical change in her husband's behavior, his wife became depressed: 'Ever since the operation, I feel lost. Before, when he was sick, we were a perfect couple. Now, he wants to live the life of a young man, go out, meet new people, all of that is intolerable! I would rather he be like he was before, always nice and docile!' The patient persisted in his desire for change: 'All these years I allowed myself to be carried like a child, because I didn't have the means to fight. That period is over, I want to get back the position I left open. I am going to take my life in hand, my life before PD.' In short, a grave marital conflict was caused by the newly regained autonomy of the patient and his wife's loss of status as caregiver. ([6]: 1812)

This story differs considerably from the first one. This patient says that under treatment he now feels like himself, whereas before he felt alienated, i.e. not himself. In this case, what is gained from the treatment is authenticity, qua implicit self-ascription at least. The patient claims that in all the years of illness he was 'asleep'. This can be interpreted as him saying that he was not aware of himself, i.e. not in a self-conscious mode and, therefore, in this sense not really 'himself'. ${ }^{21}$ From a philosophical point of view, this could mean that he did not possess any self-

\footnotetext{
$\overline{{ }^{21} \text { There seems }}$ to be a gap between not being self-conscious and not feeling like yourself. It seems like there must be some sort of minimal self-consciousness involved in the patient's experience, but that the self that he is conscious of is not really his 'true self'.
} 
reflective capacities and could not lead his life autonomously.

As he puts it after successful surgery: 'I want to regain my life, my life before PD'. In stating this, he refers to the life before his illness that was really his, his real life, he being conscious of himself and 'master of his own destiny', as one could say. During the years of illness, however, according to his own retrospective assessment, he feels he was not himself, i.e. inauthentic, alienated, and not fully conscious. His life was not really his own, existing as someone else's heteronomous object of care. This is at least how he describes his time of illness in hindsight.

With respect to authenticity and alienation, at least three points about his case are important.

First, the patient's self-ascription of authenticity is interesting. It seems that, after surgery, the patient distinguishes two modi in his life. On the one hand, there is 'mode one', the mode he experienced when he was healthy before Parkinson's disease struck him. This mode he experiences retrospectively as his 'authentic mode'. On the other hand, there is 'mode two', the mode he experienced when he became sick. He says in hindsight that this mode is one in which he was not authentic, but 'asleep' and thus alienated. Finally, once he is successfully treated via DBS and switches back to 'mode one', he begins to feel authentic again.

The second remarkable point is that this contradicts what Patient 1 had reported. Adapting the model from above, she experienced 'mode two', i.e. the mode of being diseased, as her most authentic mode. When she was sick, she had something to strive for: to overcome her disease and to lead a meaningful life despite her handicaps. The daily struggle gave her life meaning. When she returns to 'mode one' as the mode of health, however, she describes herself as feeling alienated, because she has lost her goal in life. It seems she no longer experiences herself as authentic once she is healthy.

On a theoretical level, this points towards the fact that the ascriptions of authenticity and alienation depend on subjective factors. It seems there is no general, transindividually valid correlation between being healthy and feeling authentic, and being sick and feeling alienated. On the one hand, an existentialist or phenomenological notion of authenticity, which emphasizes mortality, fits for Patient 1: a person is 'authentic' (eigentlich) only when she is confronted with her vulnerability and thereby her mortality through her disease (cf. [28]: 152) and struggles for survival. On the other hand, however, the opposite holds for Patient 2: he defines himself essentially as a healthy person and does not accept the diseased person he used to be as himself. Furthermore, the fact that there is no unifying account of the subjective experience of DBS has implications with respect to how we understand DBS treatment. Whereas the treatment for one person can be authenticity-generating, for another, it has an alienating effect.

Third, it is worth noting that Patient 2 correlates authenticity, i.e. living his own life, with autonomy. For Patient 2, in order to be himself, he must be autonomous like an adult person, not dependent and heteronomous like a child. He wants to return to the autonomous social- and work-life he led before the disease - and the treatment makes this possible.

This, of course, stands in sharp contrast to the second- and third-person perspective of his wife. According to her, her husband is alienated from himself in 'mode two', the healthy state. She complains he wants to 'live the life of a young man', i.e. a life that is not only inappropriate to him in her eyes, but actually is the life of someone else and not his. Additionally, now that she as the caregiver is no longer needed and wanted, she has lost all meaning in her life. She wants to get divorced, because she feels alienated from her relationship with a person who she no longer views as her husband.

The third case presented by Schüpbach et al. [6] reveals yet another feature of authenticity and alienation.

\section{Patient 3: 'I want to be recognized as sick'}

Patient 3, a 45-year-old female executive, married with 3 children, had levodopa-responsive PD for 6 years [...] with severe motor complications. Before the operation, she was ashamed to be sick and concealed her disease from her colleagues and employer. She invested herself in her work, assumed more and more responsibilities, and had great hopes that the operation would help her to progress in her career: 'If I'm not operated in the coming months, the beast is going to sleep. As long as I have my work, I still exist; the day I can no longer go to work, it will be as if the curtain came down on my life. 'Six months after the operation, she had no trace of a motor handicap [...]. She put off going back to work, 
however, because she felt anxious, had lumbar pain, dizziness, difficulty walking, but had no neurologic substrate. [...]. An episode of severe depression was treated successfully. Eighteen months after the operation, she had tried several times without success to go back to work:' I don't have the same ability to concentrate as before. I have a lot of work and prefer to spend my time doing other things. 'She requested unjustified sick leaves, preferred to go out, buy things on the Internet. She threatened to divorce, although there had been no marital conflict before the operation. She announced her disease to her entourage, was active in associations, and wanted to 'be recognized as sick.' In short, a loss of professional status after the operation occurred, in spite of spectacular motor improvement, which was the cause of a marital crisis. $^{22}$

Here, at first glance, the picture is very similar to the first case: now that the patient's condition has improved, she experiences leisure as authenticity, whereas she experiences work as alienating. The cured patient prefers to spend her time doing other things outside her employment, spending money on the internet and joining social activities. However, in contrast to the first case study, it is interesting to see that now that the patient's body condition is improved drastically, she somehow paradoxically wants her disease acknowledged.

Before the treatment, she had attempted to hide her disease from her family, employer, and colleagues. Now that she is better than before, it seems that she, to a certain extent, actually denies being better and

\footnotetext{
${ }^{22}$ Schüpbach et al. [6]. The patient is reported by Schüpbach et al. as saying 'If I am not operated in the coming months.' However, she rather seems to mean: 'If I am operated in the coming months ...'

${ }^{23}$ The case study mentions that the patient complains about several physical symptoms for which 'no neurological substrate' could be found. However, the reader might wonder whether these symptoms still do have a physical cause and are not only 'psychologically', but also 'physiologically' real. For instance, when the patient complains about fatigue and a lack of energy, this could be due to the switch to less medication after surgery. As the authors remark: 'Apathy after neurosurgery has been attributed both to stimulation of the STN itself [...] and to the reduction of levodopa treatment after surgery [...]' ([6], 1812). The assessment of what is more a physical and what is more a psychological symptom has to be left to medical experts. For the sake of the argument, I will here follow the authors' suggestion that the patient's unwillingness or inability to go back to work has psychological causes only.
}

does not want to recognize her own improvement. ${ }^{23}$ The fact that she demands attention for and recognition of her diseased state, even when she is 'healthier' than before, suggests that she identifies her diseased state as her authentic state. Similarly to Patient 1, the bodily self-image of Patient 3 seems to be dissociated from her mind. Her mind is still that of a sick person, although it has gained the strength to now recognize and even publicly proclaim her disease, whereas her body improved already - a fact that does not seem to have made it through to her consciousness. Her battlecry is: 'I want to be recognized as sick', now that her symptoms are much better than before surgery.

All in all, to me the case of Patient 3 reads like a story of emancipation, revelation, or even revolt. It even sounds as if she regarded her personal, retrospective coming out as a Parkinson's patient as a political mission, probably also willing to fight for the rights of other people in her situation. ${ }^{24}$

If we use the notions of alienation and authenticity, we can shed light on Patient 3's experience. We could interpret the patient's situation before treatment as alienating: she used to live a life under permanent pressure, being an ambitious working mother who has PD, and who, on the top of that, felt the need to conceal her ailment. DBS helps this patient reach a state authenticity, insofar as she is now able to be sincere, honest, and self-confident with respect to herself. In hindsight, the patient truthfully recognizes her own past condition and pays herself due respect for all she has undergone and has nevertheless achieved. Paradoxically, this happens at the very moment she experiences a substantial relief of most of her preeminent PD symptoms. Her newly gained self-confidence makes her demand full recognition for her achievements from others as well. In this vein,

\footnotetext{
$\overline{{ }^{24} \text { For a more }}$ detailed interpretation of this case, more interview materials would be needed. On the one hand, the condition of the patient after surgery is described as negative: she has quit working, is having marital problems, and spends her time spending money on the internet - and seems not to realize and appreciate her physical improvement. On the other, she has obviously gained self-confidence. It is this latter aspect of her experience that can lead one to a positive interpretation of the case, reading it as a story of emancipation. It would not be appropriate to regard her simply as self-deceived: in fact, Parkinson cannot be cured, but only its symptoms can be relieved. In this regard, the patient is right in still claiming recognition for her disease. Still, it is remarkable that her body condition seems to be split up from her self-understanding (what the authors call 'a distressed mind in a repaired body')
} 
due to the treatment, she has gained the strength to be truthful and open with the people in her life, making her disease public instead of shamefully trying to hide it. Now that her bodily symptoms have remarkably improved, it seems that the time is ripe for her to reap some 'reward' and compensation for all the hardships she underwent during her disease.

To sum up: interpreted this way, what is important in this third case study is that the patient escapes from felt-alienation through treatment and achieves a state of authenticity as a result. Here, authenticity means liberation and emancipation.

So far, I have offered an interpretation of these three case studies within the philosophical framework of authenticity and alienation; however, as I mentioned above, my interpretation differs from the conclusions that the authors of the study draw. In the following section, I want to turn my attention to their conclusions and to what, from my vantage point, is unsatisfying in their account.

\section{The Psychologists' Conclusions: Social} Maladjustment

Leaving the quantitative details aside, let's consider the conclusions drawn by Schüpbach et al. [6]. ${ }^{25}$ Conducted within the framework of a psychological and psychiatric assessment, the main aim of the study was to show that treatment via DBS can result in 'social maladjustment', i.e. in patients having difficulties getting along in their professional, social, and private lives. As the authors put it:

There was a contrast between the marked improvement in parkinsonian motor disability, activity of daily living, and quality of life and the fact that social adjustment did not improve. [...] The operation is, therefore, likely to contribute to social maladjustment $[\ldots]$ ([6]: 1816).

The authors distinguish three areas of difficulties: 'patient's experience', 'the couple', and 'professional activity’ ([6]: 1813f.).

The first category, 'patient's experience', is the most important one for this paper, and the authors of

\footnotetext{
${ }^{25}$ In order to gain a full appreciation of the study, its empirical and quantitative details are well worth reading, but it would go beyond the scope of this conceptual paper to discuss them in depth.
}

the study associate it with different problems. The most pressing issue given my purposes is that more than the half of patients articulated 'a feeling of strangeness and unfamiliarity' with themselves after surgery, saying things like 'I don't feel like myself any more', or 'I haven't found myself again after the operation'. This phenomenon is what I, from a philosophical point of view, analyzed as Patient 1's loss of authenticity and feeling of alienation, i.e. a 'relation of relationlessness' to oneself. ${ }^{26}$ Furthermore, $20 \%$ of the patients reported that they reflected negatively on the relation between their bodies and the implant: as the authors remark, three female patients 'had difficulty accepting the presence of an electronic device in their brains, saying things like 'I feel like a robot', or 'I feel like an electronic doll'. ${ }^{27}$ Among the other problems that appeared in the category of 'patient's experience' after surgery was the fact that $41 \%$ of the patients complained about a 'loss of vitality' ([6]: 1813). Moreover, as is mirrored in the title of the study already, another problem arose for patients who became aware of the abovementioned tension between their 'healed' bodies and their 'distressed minds', which were not yet able to trust in the new bodily capacities (cf. [6]: 1814). Last but not least, $41 \%$ complained of a 'loss of aim in life'. As the authors remark: ['f]ighting PD was a driving force for many patients' that is no longer there after surgery (cf. [6]: 1814).

Second, in relation to the category of 'the couple', the authors point out that 'following neurosurgery, the majority of couples had new or continuing marital conflicts' (cf. [6]: 1814).

Third, with respect to the category of 'professional activity', the authors remark that 'work became a secondary issue for many successfully operated patients' (cf. [6]: 1815).

What I want to emphasize here is the fact that the authors of the study assess the change in the patients' 'behavior as negative. As the report puts it, several

\footnotetext{
${ }^{26}$ For this formulation see Jaeggi ([25]:12) and Neuhouser, 25, see FN 10 section Felt Authenticity and Felt Alienation: Some Conceptual Clarifications of this paper.

${ }^{27}$ The researchers add that 'after struggling with the idea of being implanted with an electronic device, one patient finally coped well with it and made an artwork of her chest X-ray showing the stimulator' ([6]: 1813f.; cf. also the interpretation of [9]: 139 of this case). A similar case of successive adaptation, adjustment and finally acceptance of the device is described in Müller et al. [7]: 307f.
} 
patients' became more direct in their approach to others', became overly talkative, 'irritable, and impatient' ([6]: 1814). The authors proceed as follows:

They expressed their opinions more freely and revealed their formerly concealed PD to outsiders, as if they had become disinhibited. As a result, preexisting tension in a couple or a minor deterioration of professional performance (in terms of reliability, punctuality, correctness, persistence) could degenerate into familial conflicts or maladjustment at work. ([6]:1814)

Here, the psychologists suggest that treatment brings about negative results in the patients' social and professional lives. Indeed, the key-word in their psychological diagnosis was 'maladaptation", a term laden with negative value.

There are, of course, patients of whom I think they would willingly accept 'maladaptation' as a description of their own inner experience after surgery. To name only one example, Patient 1 utters that she does not recognize herself anymore under DBS ([6]: 1814). In this case, the negative perspectives of the psychologists and the patients indeed converge. However, there are cases, such as Patient 2 and Patient 3, where the patients feel authentic, i.e. have positive feelings after surgery, but the psychologists still assess their situation negatively.

It is these latter cases that deserve closer attention and a philosophical reevaluation. In contrast to the psychological evaluation, in these and analogous cases, my philosophical assessment suggests a different, positive way the narratives should be interpreted: after surgery, it is not maladjustment or alienation that the patients experience, but rather self-proclaimed authenticity. ${ }^{28}$ To be sure, the patients' family and colleagues have difficulty dealing with them after surgery. In this sense, the patients in question indeed seem to no longer be well-adapted to their environments. However, from a philosophical point of view, the reader might wonder whether there is anything intrinsically wrong with the new attitudes and behavior of patients who describe their

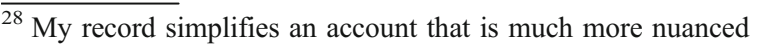
in reality. For instance, the paper gives exact figures and mentions the positive sides of stimulation as well. The authors point out that some patients describe the impact of surgery as a life-changing positive event, as a 'second birth' or as 'giving birth' ([6]: 1814). Further, the authors emphasize that, despite all the difficulties '[n]one of the patients, however, wanted to stop stimulation and go back on medication only' (cf. [6]: 1814).
}

own inner experience positively, as one of authenticity. As I show in what follows, it is not at all clear that the patients' personality change should be regarded as intrinsically negative. If the behavioral change turns out to be positive and not just negative, then this may have significant implications for the patients' selfunderstanding and future life, not to mention for how we are to assess the patients after treatment.

\section{Alienation from Alienating Conditions? A Philosophical Re-evaluation}

Whereas Schüpbach et al. [6] are of the opinion that the treatment sometimes leads to social maladjustment and thus interpret its outcome as negative, we should wonder how the patients themselves describe their change. In the patients' reports, do they describe it as a negative change? Or do they, instead, regard it as positive and as an improvement? If they, after surgery, describe their new life as authentic and their former lives with PD as alienating, [37, 38] then there is reason to suspect that those patients do regard the outcome of DBS as a positive change. Indeed, one could assume that they probably prefer not to be 'adjusted' any longer to their former lives, because those lives are something they feel alienated from. In other words: from the patients' point of view, some of them seem to have begun to feel alienated from alienating conditions, and, therefore, no longer want to adapt to them. Consequently, what appears as negative 'maladjustment' to the psychologists and to other third parties ${ }^{29}$ could be a positive experience for the patients themselves, from their subjective point of view. A philosophical perspective should pay attention to this possibility because it could contribute to a more well-informed ethical discussion of the treatment of DBS patients. ${ }^{30}$ The philosophical results become clearer if we have a look at the three case studies again.

Patient 1 states that she no longer recognizes herself after treatment. In her case, DBS seems to have led to a state of felt alienation. ${ }^{31}$ In her, treatment has not

\footnotetext{
${ }^{29}$ Cf. also Müller et al. [7]

${ }^{30} \mathrm{I}$ do not think that a philosophical interpretation is per se more adequate than the psychological one provided by Schüpbach et al. Rather, as indicated in the introduction, I think a philosophical approach could fruitfully complement the psychological assessment.

${ }^{31}$ This sounds as if a Frankfurtian concept of authenticity could be applied, cf. Frankfurt [34].
} 
brought about a positive change. However, in contrast, Patients 2 and 3, according to their reports, indeed seem to regard the treatment as authenticity-generating, in spite of the fact that the psychologists assess the outcome in the negative sense of 'maladjustment'. The story of Patient 3, as I suggested, can be interpreted positively as one of revolt and liberation. Why should be speaking out freely on one's own disease be a sign of 'disinhibition' as the authors of the study put it? Why should a society that discriminates against people who are affected by a disease and that suggests revealing their condition be an appropriate environment to which one should adapt? Maybe the conditions under which Patient 3 had been working were alienating, exploitative and inhumane themselves, putting too much pressure on her? Meanwhile, Patient 2, who explicitly states that he regards the time when he had the disease as a time of alienation, seems to now look forward to resuming his professional life. As described in detail above and according to his report, he perceives himself as being awakened to his full consciousness. Yet, he seems to now feel alienated from his marriage, and his wife expresses her alienation from his 'new personality'. From a philosophical point of view, however, I think it is by no means clear that his development should be regarded negatively as a case of 'maladjustment'. Relative to the interests of the patient himself, it could rather be that quitting this relationship (that seemed to have had its smothering sides) could even be a step towards more authenticity and autonomy for him.

If we understand cases 2 and 3 in this light, i.e. as patients breaking free from previously alienating conditions, it becomes doubtful whether they themselves regard their behavioral changes as 'maladjustment'. In this light, a philosophical analysis should consider the possibility that for them these changes could be positive, involving 'insight' or 'revelation'. 32 According to the reports,

\footnotetext{
$\overline{32}$ What strikes the reader is the gender aspect in these case studies. I wish to thank the audience in Dortmund for drawing my attention to this subject. The patient who experiences his return to his professional life as authenticity-generating and his private life as alienating is male, whereas the two patients who feel alienated from their work-life and prefer to spend their time primarily on leisure activities after DBS are female. With respect to the aspects of authenticity and alienation, this allows for at least two different interpretations: a) either the two concepts are themselves pre-formatted by society (the study stemming from France), or b) they are hollow, and are only used to conceal gender-stereotyping.
}

for patients 2 and 3, under treatment it turned out that they experienced their professional and/or love life as alienating, and that they didn't want to resume it. It seems that they eventually found new ways of leading their lives according to their new preferences.

In the Introduction, I claimed that it makes sense to talk about the patients' felt-authenticity and alienation when considering the chances and challenges of deep brain stimulation. Having discussed the case studies in this light, I have shown that the concepts of authenticity and alienation are helpful heuristic instruments in interpreting DBS cases in a philosophically meaningful way. In some cases, this even leads to a new evaluation and a new assessment of the patients that differs from the psychological one, taking the subjective experiences of authenticity and alienation into account.

\section{Conclusions}

What is the benefit of interpreting the case studies in light of the notions of authenticity and alienation?

To begin, we saw that by employing the philosophical framework of authenticity and alienation, we are led to call into question the psychological assessment of the three case studies of Parkinson patients who underwent changes in their personalities and preferences after successful treatment with DBS [6]. The psychologists interpreted the behavioral changes in the patients in a negative light, as forms of social maladjustment; however, it turned out that appreciating the subjective dimension of felt-authenticity and -alienation suggests that the patients' experiences are more nuanced than the psychologists recognized. We saw that a philosophical re-interpretation of these cases revealed that for some patients, what the psychologists called a 'state of social maladjustment' was actually experienced by the patients as a positive state, a state of authenticity'. ${ }^{33}$ This suggests that when evaluating the ethical, psychological, and social implications of behavior changes that result

\footnotetext{
${ }^{33}$ This is, at least, how I interpret the narratives of patients 2 and 3 and of what I assume is the patients' subjective experience.
} 
from DBS, the subjective state of felt-authenticity and felt-alienation should be taken into consideration.

What's more, when analyzing the case studies from a philosophical point of view, aspects of the patients' experience are emphasized, which are not fully appreciated in the psychological assessment. As we saw above, for many of the patients, their experience involved recognizing, exploring, and enacting what they regarded as their 'true selves'. In this sense, part of the patients' experiences included coming to terms with feelings of authenticity and alienation brought about by treatment. Moreover, their narratives mirror different aspects of authenticity and alienation in their relations to their partners, their own bodies, and their professional occupations. Thus, an important part of the patients' experience involved the ways in which felt-authenticity and felt-alienation was brought about through treatment via DBS. While these reported subjective dimensions seem important for our understanding of patients' experiences, they were only brought to the fore when we employed the philosophical tools of authenticity and alienation.

What I have aimed to show in this paper is that we should regard the concepts of authenticity and alienation as, at least, possible factors we need to take into account in the philosophical, ethical, and medical considerations of DBS treatment. ${ }^{34}$ Future research has to show whether the concepts of authenticity and alienation really can help contribute to a more nuanced understanding of such cases and can eventually inform ethically responsible decision making when it comes to the treatment of Parkinson patients via deep brain stimulation. But, for now, we should realize that this is research that ought to be undertaken.

Open Access This article is distributed under the terms of the Creative Commons Attribution Noncommercial License which permits any noncommercial use, distribution, and reproduction in any medium, provided the original author(s) and source are credited.

\footnotetext{
${ }^{34}$ A topic that deserves future discussion is that, from a normative point of view, in some cases, authenticity might be less important than other values such as patient safety.
}

\section{References}

1. Synofzik, Matthis, and Thomas E. Schlaepfer. 2008. Stimulating personality: Ethical criteria for deep brain stimulation in psychiatric patients and for enhancement purposes. Biotechnology Journal 3(8): 1511-1520.

2. Synofzik, Matthis \& Schlaepfer, Thomas E. 2010. 'Electrodes in the brain: Ethical criteria for research and treatment with deep brain stimulation for neuropsychiatric disorders", Brain Stimulation, 2, Online first, doi:10.1016/j.brs.2010.01.006.

3. Okun, M.S., and K.D. Foote. 2005. Subthalamic nucleus vs. globus pallidus interna deep brain stimulation: the rematch: will pallidal deep brain stimulation make a triumphant return? Archives of Neurology 62: 533-536.

4. Miyawaki, Edison, S. Perlmutter Joel, I. Tröster Alexander, et al. 2000. The behavioural complications of pallidal stimulation: A case report. Brain and Cognition 42(3): 417-434.

5. Tröster, Alexander I. 2008. Effects of deep brain stimulation on cognition, mood, and behavior in Parkinson"s disease. US Neurology 4(I): 69-72.

6. Schüpbach, M., M.L. Gargiulo, L. Welter, C. Mallet, et al. 2006. Neurosurgery in Parkinson disease: A distressed mind in a repaired body? Neurology 66: 1811-1816.

7. Müller, Oliver, Uta Bittner, and Henriette Krug. 2010. Narrative Identität bei Therapie mit 'Hirnschrittmacher. Ethik in der Medizin 22(4): 303-315.

8. Crone, Katja. 2008. Personale Identität als Orientierung bei Eingriffen ins Gehirn'. In Die ,Natur des Menschen 'in Neurowissenschaft und Neuroethik, ed. Jens Clausen et al., 123-136. Würzburg: Königshausen und Neumann.

9. Schechtman, M. 2010. Philosophical reflections on narrative and deep brain stimulation. The Journal of Clinical Ethics 21 (2): 133-139.

10. Takagi, M. 2009. Safety and neuroethical consideration of deep brain stimulation as a psychiatric treatment. Brain and Nerve 61(1): 33-40.

11. Witt, Carsten, Kuhn, Jens, Timmermann, Lars, Zurowski, Mateusz, and Woopen, Christiane. 2011. 'Deep brain stimulation and the search for identity', Neuroethics, online first, doi:10.1007/s12152-011-9100-1 http:/www.springerlink. com/content/j3710r17263nx652/fulltext.html

12. Klaming, Laura, and Pim F.G. Haselager. 2010. Did my brain implant make me do it? Questions raised by DBS regarding psychological continuity, responsibility for action and mental competence. Neuroethics. doi:10.1007/s12152-010-9093. Online first.

13. Schermer, Maartje. 2011. 'Health, happiness and human enhancement-Dealing with unexpected effects of deep brain stimulation', Neuroethics, Online first, doi:10.1007/ s12152-011-9097-5, http://www.springerlink.com/content/ 773u6m412522p396/fulltext.html

14. Carter, Adrian, Polly Ambermoon, and Wayne D. Hall. 2010. Drug-induced impulse control disorders: A prospectus for neuroethical analysis. Neuroethics. doi:10.1007/ s12152-010-9071-7. 19 april, Online first.

15. Bolt, L.L.E. 2007. 'True to oneself? Broad and narrow ideas on authenticity in the enhancement debate. Theoretical Medicine and Bioethics 28(4): 285-300.

16. Trilling, Lionel. 1971. Sincerity and authenticity. Cambridge Mass: Harvard University Press. 
17. Elliott, Carl. 2003. Better than well: American medicine meets the American dream. New York/London: Norton.

18. Taylor, C. 1989. Sources of the self. Harvard UP: Cambridge Mass.

19. Taylor, Charles. 1991. The ethics of authenticity, Cambridge Mass., Harvard UP.

20. Elliott, Carl. 1999. Bioethics, culture, and identity. New York/London: Routledge.

21. Svenaeus, Fredrick. 2010. 'The body as gift, resource, or commodity: Heidegger and the ethics of organ transplantation', Journal of Bioethical Inquiry 7: nr. 2.

22. Svenaeus, Fredrick. 2009. 'The ethics of self-change: Becoming oneself by way of antidepressants or psychotherapy?', Medicine, Health Care and Philosophy 12: nr. 2 .

23. Bublitz, Jan Christoph, and Reiner Merkel. 2009. Autonomy and authenticity of enhanced personality traits. Bioethics 23 (6): $360-374$.

24. DeGrazia, David. 2000. Prozac, enhancement, and self creation. The Hastings Center Report 30(2): 34-40.

25. Jaeggi, Rahel. 2005. Entfremdung: Zur Aktualität eines sozialphilosophischen Problems, Frankfurt a.M., Campus.

26. Neuhouser, Fredrick. 2007. Review of Rahel Jaeggi: Entfremdung: Zur Aktualität eines sozialphilosophischen Problems', Notre Dame Philosophical Reviews, online http://ndpr.nd.edu/review.cfm?id=10243, December 2010.

27. Kraemer, Felicitas. 2010. 'Authenticity anyone? The Enhancement of emotions via neuropsychopharmacology. Neuroethics. doi:10.1007/s12152-010-9075-3. Online first.

28. van Hooft, Stan. 2006. Caring about health. England: Ashgate Publishing Limited.

29. Leentjens, A.F.G., V. Visser-Vandewalle, Y. Temel, and F.R.J. Verhey. 2004. Manipuleerbare wilsbekwaamheid: een ethisch probleem bij elektrostimulatie van de nucleus subthalamicus voor ernstige ziekte van Parkinson'. Nederlandse Tijdschrift voor Geneeskunde 148(28): 194198. 10 July.
30. Erler, Alexandre. 2010. Does memory enhancement threaten our authenticity? Neuroethics. doi:10.1007/s12152-010-9090-4. Online first.

31. Parens, E. 2005. Authenticity and ambivalence: Toward understanding the enhancement debate. The Hastings Center Report 35(3): 34-41.

32. Parens, Erik. (ed.). 1998. Enhancing human traits. Ethical and social implications, Washington D.C.: Georgetown UP.

33. Schlaepfer, Thomas E., and Joseph J. Fins. 2010. Deep brain stimulation and the neuroethics of responsible publishing: when one is not enough'. Journal of the American Medical Association 303(8): 775-776. 2, 24.

34. Frankfurt, Harry. 1988. The importance of what we care about. Cambridge: Cambridge UP.

35. Berghmans, R.L.P., and G.M.W.R. de Wert. 2004. 'Commentaar: Wilsbekwaamheid in de context van elektrostimulatie van de hersenen', Nederlandse. Tijdschrift voor Geneeskunde 148: 1373-1375.

36. Fins, Joseph J. 2009 'Deep brain stimulation, deontology and duty: the moral obligation of non-abandonment at the neural interface', Journal of Neural Engineering. 6: doi:10.1088/1741-2560/6/5/050201

37. Munhoz, R.P., G. Fabiani, N. Becker, et al. 2009. Increased frequency and range of sexual behavior in a patient with Parkinson's disease after use of pramipexole: A case report. The Journal of Sexual Medicine 6: 1177-1180.

38. Singh, I. 2007. Clinical implications of ethical concepts: Moral self-understandings in children taking methylphenidate for ADHD. Clinical Child Psychology and Psychiatry 12: $167-182$.

39. Jaeggi, Rahel 2005. Entfremdung Zur Aktualität eines sozialphilosophischen Problems. Campus Verlag, Frankfurt am Main.

40. Taylor, Charles 1992. The Ethics of Authenticity. Cambridge Mass: Harvard UP.

41. Guignon, Charles B. 2004. On Being Authentic. London: Routledge. 